\title{
Hypolipidemic activity of Lannea coromandelica Houtt. leaves in Triton X-100 induced hyperlipidemic rats
}

\author{
Galanki Vasantha1, A. Venkatesham ${ }^{2, *}$, CH. Dayakar ${ }^{3}$ \\ ${ }^{\mathbf{1}}$ Associate Professor, ${ }^{\mathbf{2}, 3}$ Principal, Dept. of Pharmacology, ${ }^{\mathbf{1}, 2}$ SVS Group of Institutions, School of Pharmacy, Warangal, Telangana, \\ ${ }^{3}$ Dhanvanthari Institute of Pharmaceutical Sciences, Sujathanagar, Khammam, Telangana, India
}

*Corresponding Author: A. Venkatesham

Email: venkatkuc@gmail.com

\begin{abstract}
Lannea coromandelica Houtt have multiple pharmacological activities including anti-inflammatory, aphrodisiac hypotensive, anti microbial, ulcerative stomatitis, wound healing, leprosy, gout, elephantiasis and cholera. Therefore, the present study is taken up to evaluate the hypolipidemic activity of ethanolic leaf extract of L.coromandelica. The ethanolic leaf extract was evaluated for its acute toxicity $(2000 \mathrm{mg} / \mathrm{kg})$ and for hypolipidemic activity $(100$ and $200 \mathrm{mg} / \mathrm{kg})$ in Triton X-100 (100mg/kg, i.p) induced model for 7 days. However, the obtained statistical data indicated a significant decrease in the total cholesterol, triglycerides, LDL cholesterol, VLDL cholesterol and increase in the HDL cholesterol, with reference to the standard drug Atorvastatin $(10 \mathrm{mg} / \mathrm{kg}, p . o)$. These results revealed that L. coromandelica has beneficial effect in reducing the blood lipid levels indicating its efficient hypolipidemic activity.
\end{abstract}

Keywords: Lannea coromandelica, Atorvastatin, Triton-X, Hyperlipidemia.

\section{Introduction}

Hyperlipidemia is well known for its contribution in the prevalence of coronary heart disorders. ${ }^{1}$ Hyperlipidemia is characterized by the increase in the serum low density lipoprotein, very low density lipoprotein, total cholesterol and decrease in the high density lipoprotein levels. ${ }^{2}$ Hence, it is the major risk factor for the premature development of cardiovascular complications and atherosclerosis. ${ }^{3}$ The undesirable side effects have made scientists look towards plant based hypolipidemic agents. ${ }^{4}$ Plants play a major role in the discovery of new therapeutic agents and are considered reliable sources of biologically active substances including antioxidants, hypoglycemic and hypolipidemic agents. ${ }^{5}$ The principle components of Lannea Coromandelica includes flavonoids, flavonols, sterols, gums and mucilage. ${ }^{6}$ Several flavonoid containing plants serve as a hidden wealth $^{7}$ in the treatment of hypolipidemia ${ }^{8}$ and diabetes mellitus. ${ }^{9}$ Therefore, the present study was designed to evaluate the antihyperlipidemic activity of ethanolic leaf extract of $L$. coromandelica in Triton $\mathrm{x}-100$ induced hyperlipidemic rats.

Preparation of Drug Solution: The standard drug Atorvastatin and ethanolic leaf extract of L.coromandelica were dissolved in $0.9 \%$ Sodium chloride in water. ${ }^{10}$ The prepared solutions were administered orally to the wistar rats with the help of an intragastric catheter. ${ }^{11}$

Experimental Animals: All the protocols and experiments used in the present study were approved by the Institutional Animal Ethics Committee (IAEC). ${ }^{12}$ Healthy, adult male Wistar rats $(180-250 \mathrm{~g})$ were divided into 5 groups of 6 animals per cage. ${ }^{12}$ All the rats were maintained under standardized laboratory conditions and provided free access to the balanced pellet diet throughout the experimental period. ${ }^{12}$

Acute Oral Toxicity Study: Healthy male wistar rats (180$250 \mathrm{~g})$ were divided into 6 groups $(\mathrm{n}=6)$. Group I-V animals were orally fed with graded doses of ethanolic leaf extracts of L.coromandelica in increasing dose levels of 100, 200, 400,800 and $2000 \mathrm{mg} / \mathrm{kg}$ body wt./rats/day, while group VI (untreated) served as control. ${ }^{13}$ All the treated rats were kept under continuous observation for the first $2 \mathrm{~h}$ for any gross changes and symptoms including behavioral, neurologic and autonomic profiles or any other symptoms of toxicity and mortality if any, for the next $6 \mathrm{~h}$ and then again at $24 \mathrm{~h}, 48 \mathrm{~h}$ and $72 \mathrm{~h}$ for any lethality or death. ${ }^{14}$

Experimental Induction of Hypolidemia in Rats: Induction of hyperlipdemia was carried out by single intraperitoneal injection of freshly prepared solution of Triton X-100 $(100 \mathrm{mg} / \mathrm{kg})$ dissolved in physiological saline. ${ }^{15}$ All the animals should be kept for overnight fasting for 18 hours before the treatment. The animals were allowed to be maintained at room temperature in plastic cages. ${ }^{15}$

\section{Study Design}

The rats were grouped into five with six rats in each group. ${ }^{12}$

Group I: Rats were given normal saline of $0.9 \%$ w/v p.o. and served as normal control.

Group II: Rats were given Triton X-100 (100mg/kg, i. p.)

Group III: Rats were given Triton X-100 (100mg/kg, i. p.) and $L$. coromandelica leaf extract $(100 \mathrm{mg} / \mathrm{kg}$, p.o. $)$

Group IV: Rats were given Triton X-100 (100mg/kg, i. p.) and $L$. coromandelica extract $(200 \mathrm{mg} / \mathrm{kg}$, p.o. $)$

Group V: Rats were given Triton-X $100(100 \mathrm{mg} / \mathrm{kg}$, i.p) and Atorvastatin $(10 \mathrm{mg} / \mathrm{kg}$, p.o $)$.

On the $8^{\text {th }}$ day of treatment, all the blood samples were collected under mild ether anesthesia by retero-orbital sinus puncture method, in the heparinized tubes. ${ }^{12}$ All the collected blood samples were centrifuged for 5 minutes at $3000 \mathrm{rpm}$ and were stored at $4^{\circ} \mathrm{C}$. Furher, all the samles were analysed for serum Triglycerides (TG),Total Cholesterol (TC), High Density Lipoprotein Cholesterol (HDL-C), Low Density Lipoprotein Cholesterol (LDL-C), Very Low 
Density Lipoprotein Cholesterol (VLDL-C), and Atherogenic Index (AI). ${ }^{12}$

Biochemical Analysis: Plasma lipid levels include TC, TG and HDL-C were carried out using commercial kits from Qualigens diagnostics, Mumbai, India and LDL-C in plasma was calculated as per Friedewald estimation, ${ }^{16}$

LDL-C $=$ TC-HDL-TG/5.

\section{Statistical Analysis}

All the obtained results were expressed as mean \pm standard error. ${ }^{17}$ The obtained data was analyzed by OneWay Analysis of Variance (ANOVA) and Dunnett's multiple comparison tests. ${ }^{17}$ However, differences between the data were considered significant at $P<0.05$. $^{17}$

\begin{abstract}
Results
Effect of LC Leaf Extract on Acute Toxicity Study: No behavioural changes were observed. ${ }^{10}$ No toxicity or death at the given dose levels was observed. The $\mathrm{LD}_{50}$ of the ethanolic leaf extract of L.coromandelica was found to be more than $2000 \mathrm{mg} / \mathrm{kg} .{ }^{11}$ Whereas as per Organization for Economic Co-operation and Development (OECD) guidelines-423 it is $2000 \mathrm{mg} / \mathrm{kg} .{ }^{11}$ So it was proved that the extracts were not having any toxic effects. Hence, on the basis of these above observations, the biological doses were fixed as 100 and $200 \mathrm{mg} / \mathrm{kg}$ body weight for ethanolic extracts for further treatments. ${ }^{10,11}$ No mortality was found at the maximum tested dose level of $2000 \mathrm{mg} / \mathrm{kg} .{ }^{11}$ Acute toxicity study indicated the non-toxic nature of the ethanolic leaf extract of L.coromandelica.
\end{abstract}

\section{Antihyperlipidemic Activity}

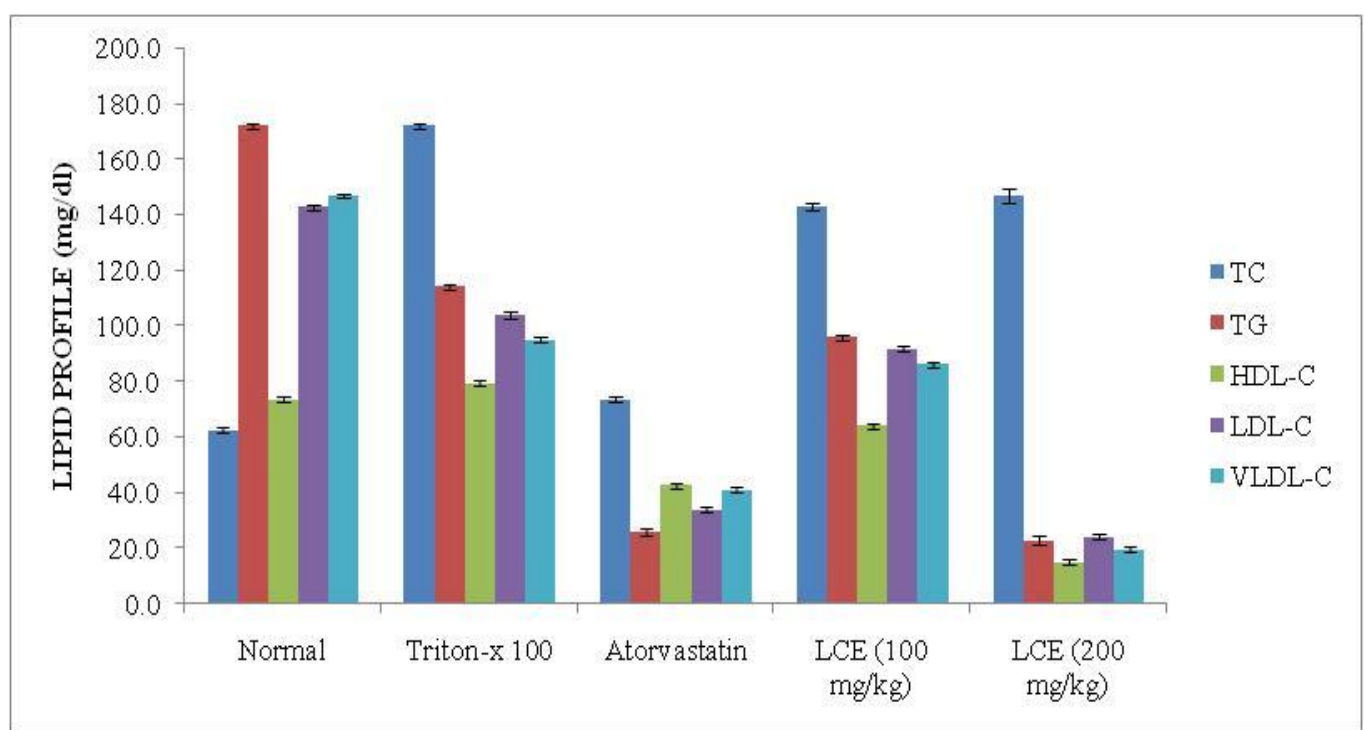

Fig. 1: Effect of LC leaf extract on serum TC, TG, HDL-C, LDL-C, VLDL-C levels in Triton X-100 induced hyperlipidemic rats on $7^{\text {th }}$ day (mean \pm SEM)

In Fig. 1, Triton X-100 induced hyperlipidemic rats showed a significant increase in serum contents of TG, TC, LDL-C, and VLDL-C and decrease in the HDLcholestero. ${ }^{18}$ Whereas, in rats treated with ethanolic extract of $L$. coromandelica (LCE) $(100 \mathrm{mg} / \mathrm{kg}$ and $200 \mathrm{mg} / \mathrm{kg}$ ) there was a significant decrease in the TG, TC, LDL-C, and VLDL-C and increase in the HDL-C, when compared with control group of rats. ${ }^{18}$ The change of Atherogenic Index in control and treated rats was shown in Fig. 2. It shows that the cholesterol induction significantly affects the cardio vascular risk markers. ${ }^{19}$ Whereas, AI was statistically increased in control group $75 \%$ compared with the values found in their normal control group. 


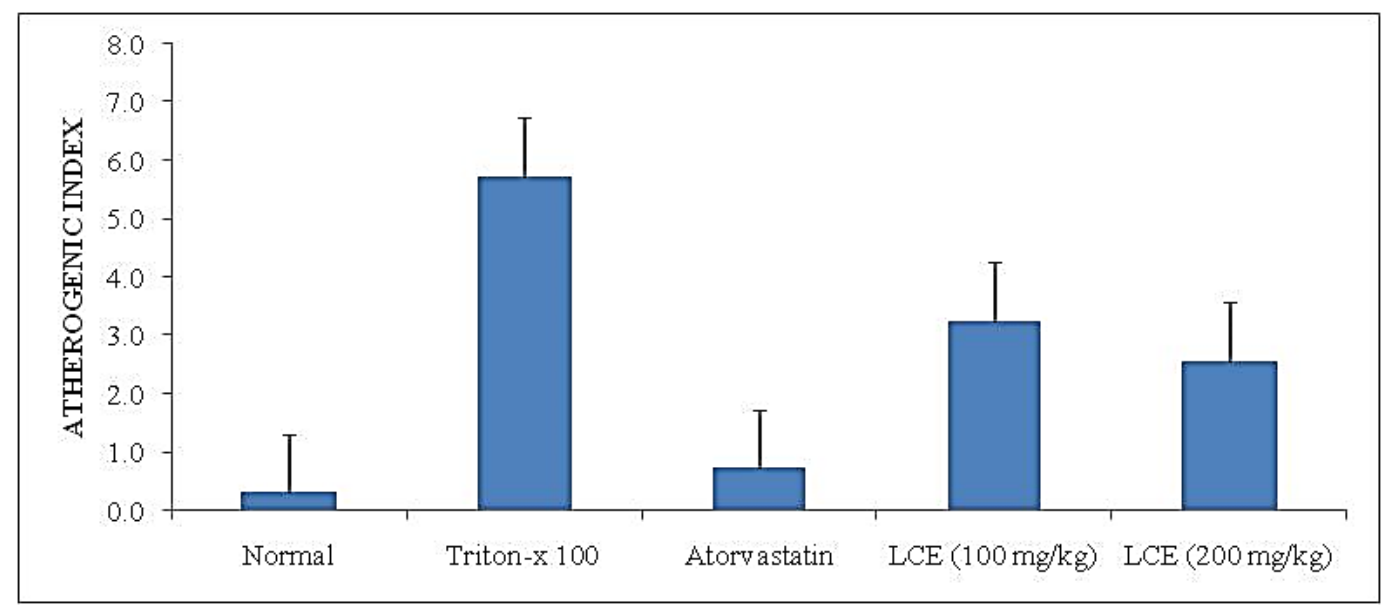

Fig. 2: Atherogenic index

\section{Discussion}

During the pilot study, the ethanolic leaf extract of L.coromandelica produced significant antihyperglycemic activity at a doses of 100 and $200 \mathrm{mg} / \mathrm{kg} \mathrm{b.w}$ in diabetic treated rats. ${ }^{20}$ The present study was performed to assess the hypolipidemic activity and to prove its claim in diabetes related complications..$^{21}$ However, Insulin deficiency leads to various metabolic alterations including increased blood glucose level, increased levels of cholesterol and triglycerides. ${ }^{22}$ All the obtained results indicated that the ethanolic leaf extract of L.coromandelica showed a significant decrease in the serum TC, TG, LDL-C, VLDL-C levels and increase in the HDL-C levels in Triton X-100 induced hyperlipidemic rats at a dose of $200 \mathrm{mg} / \mathrm{kg} \mathrm{b.wt.}{ }^{22}$ It is suggested that the hypoglycemic and hypolipidemic properties of L.coromandelica leaf extract could be mainly due to the presence of its major components including flavonoids like quercetin, isoquercetin and kaempferol; flavonols like leucocyanidine, physicion and leucodelphidin. ${ }^{23}$ However, further studies are required to prove hypolipidemic action of L.coromandelica.

\section{Conclusion}

In accordance with these results, it may be confirmed that the hyolipidemic activity of $L$. coromandelica is due to the presence of various phytochemical constituents including flavonoids, glycosides and alkaloids. ${ }^{23}$ Inconclusion, it can be said the ethanolic leaf extract of $L$. coromandelica exhibited a significant hypolipidemic effect at the dose of $200 \mathrm{mg} / \mathrm{kg}$ body weight. Further studies are required to establish the efficacy of $L$. coromandelica as a hypolipidemic drug.

\section{References}

1. Grundy SM. Cholesterol and coronary heart disease: a new era. J Am Med Assoc. 1986;256:2849-2858.

2. Saravanan, Rajendra Prasad N, Pugalandi KV. "Effect of Piper betle leaf extract on alcoholic toxicity in the rat brain." J Med Food. 2003;6, 261-265.

3. Goldstein JL, Schrott HG, Hazzard WR, Bierman EL, Motulsky AG. "Hyperlipidemia in coronary heart disease II. Genetic analysis of lipid levels in 176 families and delineation of a new inherited disorder, combined hyperlipidemia." J Clin Investig. 1973;52:1544-1568.

4. Kaur J, Singh P, Sowers JR.”Diabetes and cardiovascular diseases." Am J Ther. 2002;9:510-515.

5. Marles RJ, Farnsworth N. "Antidiabetic plants and their active constituents." Phytomed. 1995;2:137-189.

6. Reddy AK, Joy JM, Kumar A. "Lannea coromandelica: The researcher's tree." J Pharm Res. 2011;4:577-579.

7. Elder C. "Ayurveda for diabeties mellitus: A review of the biomedical literature." Altern Therap Health Med. 2004;10:4450 .

8. Srinvasan K. "Plant foods in the management of diabetes mellitus: Spices as beneficial antidiabetic food adjuncts." Int $J$ Food Sci Nutr. 2005;56,399-414.

9. Badole S, Patel N, Bodhankar S, Jain B, Bhardwaj S. Antihyperglycemic activity of aqueous extract of leaves of Cocculus hirsutus (L.). Diels in alloxan-induced diabetic mice.” Indian J Pharmacol. 2006;38:49-53.

10. Rohit G, Kim Kah Hwi, Rajeev K, Ravi Chandra V, Sartaj Banu M. Antihyperlipidemic potential of Albizia amara (Roxb) Boiv bark against Triton X-100 induced hyperlipidemic condition in rats. Pharmacogn Res. 2014;6(4):267-273.

11. Saleem U, Riaz S, Ahmad B, Saleem M. Pharmacological Screening of Trachyspermum ammi for Antihyperlipidemic Activity in Triton X-100 Induced Hyperlipidemia Rat Model. Pharmacogn Res. 2017;9:34-40.

12. Gulati R, Agarwal D.K, Hossain M.M, Ali R, Srivastava U. Study of serum lipid profile changes in Met-Enkephalin treated rats. Indian J Physiol Pharmacol. 2003;47:357-362.

13. Organization for Economic Co-operation and Development (OECD), Guidance document on acute oral toxicity testing. Paris, Environmental Directorate. 2001;1-14.

14. Ghosh M.N. "Fundamentals of Expt. Pharmacology" 1984;192-194.

15. R. Gulati, D.K. Agarwal, M.M. Hossain, R. Ali, U. Srivastava. Study of serum lipid profile changes in Met- Enkephalin treated rats. Indian J Physiol Pharmacol. 2003;47:357-362.

16. Friedewall WI, Levy RI, Fredrickson DS. Estimation of the concentration of low density lipoprotein cholesterol in plasma, without use of the preparative ultracentrifuge. Clin Chem. 1972;18:499-504.

17. Ashok S Ashish K, Tara C, Manoj K, Kailash CY. Antidiabetic and Antihyperlipidemic Activity of Cucurbita maxima Duchense (Pumpkin) Seeds on Streptozotocin Induced Diabetic Rats. J Pharmacogn Phytochemistry. 2013;6:108-116.

18. Mohale DS, Dewani AP, Saoji AN, Khadse CD. Antihyperlipidemic activity of isolated constituents from the fruits of Lagenaria siceraria in albino rats. Int J Green Pharm. 2008;2:104-107. 
19. Yadav JP, Sushila Saini, Kalia AN, Dangi AS. Hypoglycemic and hypolipidemic activity of ethanolic extract of Salvadora oleoides in normal and alloxan-induced diabetic rats. Indian $J$ Pharmacol. 2008;1:23-27.

20. Vasantha G, Venkatesham A, Dayakar CH. Antidiabetic activity of Lannea Coromandelica Houtt. leaves in alloxan induced diabetic rats. Int J Pharm Biol Sci. 2014;4:108-114.

21. Chude MA, Orisakwe Oe, Afonne OJ, Gamenial KS, Vantau $\mathrm{OH}$, Obi E. Hypoglycaemic effect of the aqueous extract of Boerhavia diffusa leaves. Indian J Pharm. 2001;33:215-216.

22. Ribes G, Dacosta C, Loubatieres-Mariani MM, Physics Res. 1987;1:38.
23. Venkateshwarlu V, Kokate CK, Rambhau D, Veerashame, Planta Medica, 1993;59:391.

How to cite this article: Vasantha G, Venkatesham A, Dayakar CH. Hypolipidemic activity of Lannea coromandelica Houtt. leaves in Triton X-100 induced hyperlipidemic rats. Indian $\mathrm{J}$ Pharm Pharmacol. 2018;5(4):207-210. 